\title{
Look who's talking now: Cancer in primary care on Twitter. An observational study
}

\author{
Kristi M Milley ${ }^{1 *}$, Sophie A Chima ${ }^{1}$, Kara-Lynne Cummings ${ }^{1}$, Jon D Emery ${ }^{1}$ \\ ${ }^{1}$ Primary Care Collaborative Cancer Clinical Trials Group, Centre for Cancer \\ Research and Department of General Practice, Faculty of Medicine, Dentistry and \\ Health Sciences, University of Melbourne, Victorian Comprehensive Cancer Centre, \\ Melbourne, Australia
}

*For correspondence: kristi. milley@unimelb.edu.au

Twitter: @kristi_milley

Competing interest: The authors declare that no competing interests exist.

Received: 19 May 2020

Accepted: 17 July 2020

Published: 06 January 2021

(This article is Open Access: CC BY license (https://creativecommons.org/licenses/by/4.0/)

Author Keywords: primary health care, neoplasms, social media, twitter, general practitioners, cancer

Copyright (C) 2020, The Authors; DOI:10.3399/

bjgpopen20X101134

\begin{abstract}
Background: Twitter is a microblogging platform that helps share information. It is a dynamic tool that has been embraced by many user types including consumers and healthcare professionals (HCPs). Currently, there are no data on how cancer in primary care features on Twitter.
\end{abstract}

Aim: To explore the type of users and information shared about cancer in primary care on Twitter.

Design \& setting: A descriptive exploratory study took place of publicly available Twitter data.

Method: Tweets were searched between July 2015 and June 2017 for 'GP', 'general practice', 'primary care', or 'general practitioner' in conjunction with 'cancer'. A $20 \%$ random sample was coded for geographic location, user type, type of tweet, and theme. Tweet sentiment was analysed using $\mathrm{R}$ package sentimentr. Content that gained traction was compared by combining original tweets, retweets, favourites, and duration.

Results: There were a total of 3413 tweets from 1611 users in 44 countries. Consumers were the largest user group followed by health organisations, healthcare professionals, and the media. The most common theme across user types was diagnostic delay. Other themes that emerged included cancer screening, symptom awareness, and early diagnosis. Consumers published more negative tweets, particularly in relation to diagnostic delay. Health organisations focused on symptom awareness and screening. Over half of media tweets were stories that featured delayed diagnosis or screening.

Conclusion: A broad range of users engage with Twitter to share information about cancer in primary care. Content is different between user groups, but diagnostic delay and symptom awareness are common themes. Healthcare and professional organisations may need to consider approaches to counter negative messages about diagnostic delay.

\section{How this fits in}

Primary care plays an important role in the prevention, early detection, and diagnosis of cancer. ${ }^{1}$ There are also emerging opportunities to further integrate primary care in cancer follow-up and survivorship care. ${ }^{2,3}$ Twitter is a potential platform to communicate this message to different groups of stakeholders, including those at higher risk of cancer. It is an important social media tool that can be used for speed and brevity to communicate with a range of users. This is the first study to explore what content different users share about the role of primary care across the cancer continuum. It provides a foundation to better understand the public perception of primary care in this context. 
This understanding will allow future research toleverage social media exposure to engage users with content designed to improve awareness of cancer and cancer symptoms, as well as the role of their GP in that journey from prevention through to survivorship.

\section{Introduction}

Social media are powerful communication platforms that are used by over $70 \%$ of the general public. ${ }^{4} \mathrm{At}$ least half of adult internet users search for or share health-related information. ${ }^{5}$ Increasing knowledge and exchanging advice are two key reasons people engage with social media. ${ }^{6}$ There is great potential for education and communication with the public to disseminate key health messages. ${ }^{7-9}$ The most common social media platforms that feature in health are Facebook and Twitter. ${ }^{9}$ These applications provide a platform for creating ${ }^{10-13}$ and engaging different communities, ${ }^{14,15}$ improving information exchange and communication, ${ }^{16-23}$ and educating a wide range of users. ${ }^{12,24-28}$

Twitter is a microblogging platform that helps capture and share bite-sized pieces of information. Users can share images and video with text up to 280 characters. Launched in 2006, by early 2019 Twitter had grown to nearly 321 million monthly users. ${ }^{29}$ The intersection of Twitter, oncology, education, and communication has been previously studied along with its impact and value for $\mathrm{HCPs}^{18}$ including oncologists or haematologists, ${ }^{21,22,30}$ radiologists, $^{15}$ and surgeons. ${ }^{10}$ This has been reviewed in a variety of contexts including scientific conferences, ${ }^{23,31,32}$ networking and education, ${ }^{33,34}$ and improving information access. ${ }^{10,18,21,35}$

In the context of public and patient engagement, there is evidence about the role of Twitter in cancer awareness, ${ }^{36,37}$ developing cancer social networks ${ }^{16}$ and reports of content analysis of cancerrelated tweets. ${ }^{11,27,28,38-42}$ Twitter-based interventions have targeted cancer awareness, ${ }^{26}$ patient education, resource access and support, ${ }^{12}$ prevention, ${ }^{25}$ and screening. ${ }^{14,40}$ This evidence is almost exclusively from a secondary or tertiary care perspective, despite the important role primary care and GPs have in the prevention, detection, and early diagnosis of cancer. ${ }^{43}$

As social media becomes increasingly popular it is important to understand how users promote and discuss specific topics. This understanding is an essential foundation to successfully developing targeted campaigns for cancer, which actively engage users and that translate into consumer actions. To date, there is no evidence on how the role of primary care and GPs in cancer are shared and discussed on Twitter. This exploratory study aimed to describe the different types of users and content shared about cancer in primary care, including what type of information generates more user engagement.

\section{Method}

\section{Search strategy and data collection}

Publicly available English language tweets between 30 June 2015 and 30 June 2017 were searched for the terms 'GP' or 'general practitioner' or 'primary care' and 'cancer'. As collection and analysis of these publicly available tweets was an observational study and did not require interaction with any human subjects, it was exempt from institutional review. ${ }^{44,45}$ Tweets were identified, collected, and extracted through a data-services provider, Podargos (Calgary, Canada). A random number generator (Microsoft Excel 365) was used to randomly extract $20 \%$ of the tweets collected. Manual coding of the full sample set was not feasible, so a $20 \%$ sample size was selected guided by random extraction in existing studies. ${ }^{36,41,46}$

\section{Data coding}

Tweets were assessed for relevance to cancer in primary care. Relevant tweets were then manually coded for the user type, tweet type, and geographic location. The user was determined by reading the biography and most recent tweets of the user account. To compare discussion of the most common cancer types, text was further searched for the terms 'colorectal', 'bowel', 'colon', 'skin', 'melanoma', 'lung', 'prostate', 'prostrate' (sic), 'ovar*', 'cerv*', and 'pancrea*' (the asterisk acts as a wildcard character, to capture within the search results variants that begin with the specified letter string; for example, 'cerv*' would return cervix, cervical, etc). The dataset was coded by one researcher 
(KM) and the final complete dataset was reviewed by a second researcher (SC) to validate coder reliability. Any conflicts were resolved in consultation with a third team member (JE).

\section{Data analysis}

\section{Descriptive analysis}

Tweets were provided, coded, and analysed in Microsoft Excel. Descriptive statistics were used to summarise the user type, location, number of tweets per tweet type, and content theme. A quantitative content analysis was used to analyse tweets. A high-order review of tweets followed by an inductive coding approach was used to identify tweet themes. Given the brevity and succinct nature of tweets, each was coded for up to two themes.

\section{Sentiment analysis}

The overall sentiment of tweets was determined using RStudio (version 1.0.153) ${ }^{47}$ and the package sentimentr (version 2.6.1). ${ }^{48} \mathrm{~A}$ library of around 6800 English words, with predetermined sentiment scores, were used to determine whether the tweets were positive, negative, or neutral. ${ }^{49,50}$ The word 'cancer' was removed from the library before being analysed, as the sentiment library classified cancer as a negative word, which would skew analysis. The library also included incorrect spellings of words frequently misspelled on social media. The package scores a tweet between -6 to +6 , with -6 being the most negative and +6 being the most positive score.

\section{Content engagement}

The top stories were determined by reviewing the tweet content and any external links to group together tweets about the same story. The total number of tweets for each story plus the total number of retweets and likes was used to rank the most popular stories. The duration of these stories was determined by calculating the number of active days on Twitter based on the date of the first and last tweet about each story.

Table 1 Summary of the type of user and frequency of users and tweets

\begin{tabular}{lcc}
\hline User type & Users, $\mathbf{n}(\%)$ & $\begin{array}{c}\text { Tweets, } \boldsymbol{n} \\
(\%)\end{array}$ \\
\hline Consumer & $413(25.6)$ & $457(21.5)$ \\
\hline Health organisation & $354(22.0)$ & $581(27.3)$ \\
\hline Healthcare professional & $250(15.5)$ & $297(14.0)$ \\
\hline Media & $229(14.2)$ & $350(16.4)$ \\
\hline Other & $202(12.5)$ & $258(12.1)$ \\
\hline Unknown & $163(10.2)$ & $186(8.7)$ \\
\hline Total & $1611(100)$ & $2129(100)$ \\
\hline
\end{tabular}

Table 2 Summary of tweet origins by geographic location

\begin{tabular}{lc}
\hline Location & $\begin{array}{c}\text { Tweets, } \\
\text { n }\end{array}$ \\
\hline UK & 1078 \\
\hline Unknown & 370 \\
\hline US & 308 \\
\hline Australia & 139 \\
\hline Canada & 74 \\
\hline Ireland & 33 \\
\hline New Zealand & 12 \\
\hline Spain & 11 \\
\hline India, Nigeria, South Africa & 10 \\
\hline Greece, Pakistan & 8 \\
\hline Egypt & 6 \\
\hline Belgium, France, Germany & 4 \\
\hline Colombia, Indonesia, Japan & 3 \\
\hline China, Italy, Nepal, Peru, Saudi Arabia & 2 \\
\hline Cyprus, Czech Republic, Ethiopia, Israel, & 1 \\
\hline Mamaica, Kenya, Malaysia, Maldives, & \\
\hline Philippines, Russia, Singapore, Sweden, & \\
\hline Rows & \\
\hline
\end{tabular}

Rows with more than one country indicate those countries produced the same number of tweets. 


\begin{tabular}{|c|c|c|c|c|c|c|}
\hline $\begin{array}{l}\text { Diagnostic delay } \\
\quad(n=407)\end{array}$ & $\begin{array}{l}\text { Symptom awareness } \\
(n=283)\end{array}$ & $\begin{array}{l}\text { Screening } \\
(n=193)\end{array}$ & $\begin{array}{l}\text { Survivorship } \\
(n=106)\end{array}$ & $\begin{array}{l}\text { Early diagnosis } \\
\qquad(n=88)\end{array}$ & $\begin{array}{l}\text { Health system } \\
\quad(n=76)\end{array}$ & $\begin{array}{l}\text { Patient barriers } \\
\quad(n=51)\end{array}$ \\
\hline $\begin{array}{c}\text { At least one in three } \\
\text { cancer patients } \\
\text { diagnosed in A\&E } \\
\text { had their symptoms } \\
\text { missed at least three } \\
\text { times by their GP. } \\
\text { https://t.co/6mMF3 } \\
\text { UrVHX. }\end{array}$ & $\begin{array}{c}\text { The main symptoms } \\
\text { of lung cancer are a } \\
\text { persistent cough, } \\
\text { chest infection, } \\
\text { breathlessness and } \\
\text { coughing up } \\
\text { blood. Ask your } \\
\text { GP for advice \#LCAM }\end{array}$ & $\begin{array}{l}\text { It's prostate cancer } \\
\text { awareness week. If } \\
\text { you're over } 50 \text { or } \\
\text { have symptoms, } \\
\text { please go to your GP } \\
\text { for a screening. IT'S } \\
\text { ONLY A FINGER. }\end{array}$ & $\begin{array}{c}\text { Review of Primary } \\
\text { Care Provider Models } \\
\text { in Care of Cancer } \\
\text { Survivors Shows } \\
\text { Opportunity for } \\
\text { Enhancement } \\
\text { https://t.co/vxB7HIk } \\
\text { bd1 \#Health? }\end{array}$ & $\begin{array}{c}\text { Don't be put off } \\
\text { going to your GP. } \\
\text { Early diagnosis is } \\
\text { vitally important } \\
\text { \#detectcancerearly } \\
\text { @Bowel_Cancer_UK } \\
\text { https://t.co/nBEXrCr } \\
\text { dpt } \\
\text { https://t.co/au3POSy } \\
\text { bvG }\end{array}$ & $\begin{array}{l}\text { \$169 to see a } \\
\text { GP: permanent } \\
\text { resident with } \\
\text { cancer shows } \\
\text { what it will be } \\
\text { like when } \\
\text { Abbott kills off } \\
\text { Medicare } \\
\text { http://t.co/pe9g } \\
\text { X04XBN }\end{array}$ & $\begin{array}{l}\text { Research by } \\
\text { @CR_UK shows } \\
\text { that people often } \\
\text { don't report } \\
\text { \#cancer } \\
\text { symptoms } \\
\text { because they } \\
\text { worry about } \\
\text { wasting GP's time } \\
\text { https://t.co/lajOs } \\
\text { oYmVG }\end{array}$ \\
\hline
\end{tabular}

Figure 1 Key themes identified and representative tweets of each theme

Overall, users' tweets fitted into one of six categories. These were as follows: sharing news stories about cancer in primary care; promoting results of research studies; promoting a new resource, either for HCPs or consumers; promoting continuing education opportunities; promoting a funding opportunity; or sharing a personal statement.

Many of the tweets analysed mapped closely to a single aspect of the cancer care continuum. From this, themes that emerged included cancer symptom awareness, prevention, screening, diagnostic delay, survivorship, and palliative care. The most common theme across user types was about a delayed cancer diagnosis (19\%). This was followed by symptom awareness (13\%), cancer screening (9\%), survivorship (5\%), and early cancer diagnosis (4\%). Other themes were about health system structure (4\%) and patient barriers related to investigating possible cancer symptoms (2\%) (Figure 1).

Some themes were more common to a specific user type. The most common theme of consumer tweets was a personal comment about their own experience of cancer or that of a friend or family member, in particular about perceived diagnostic delay (Figure 2). This was also a strong theme of media-user tweets (Figure 2). A second theme that featured strongly were stories around cancer screening, often highlighting the importance of primary care in increasing screening participation. HCPs also shared content about diagnostic delay, as well as more content about screening and survivorship (Figure 2). The strongest theme in health organisation tweets was cancer symptom awareness (Figure 2).

A third of tweets contained text about a specific tumour $(n=739 / 2129)$. Colorectal cancer (33\%) was the most common tumour type followed by breast (18\%); skin (17\%), including both melanoma and non-melanoma skin cancers; lung (11\%); and prostate (9\%).

Overall, all user groups, except HCPs, produced tweets that were classified as mildly negative with their average score being close to neutral (0). Consumers' tweets had the most negative scores (Table 3).

The top three stories shared by users that produced the greatest engagement were as follows: (1) 'GP criticises colleagues who failed to diagnose her cancer'; (2) 'GPs being paid not to refer cancer patients'; and (3) 'Patients suspecting cancer put GP listening skills ahead of shorter wait times'. These three stories featured on Twitter for between 6 and 160 days (Figure 3).

\section{Discussion}

\section{Summary}

This is the first study to explore the content of tweets about cancer in primary care. Taking into consideration the complexity of a search strategy that could identify all relevant tweets, the number of tweets identified over the 2-year search period highlights that cancer in primary care is a small, niche 
Table 3 Summary of sentiment analysis scores by user type

\begin{tabular}{lcccccccccccccc}
\hline & \multicolumn{11}{c}{ Sentiment score } & \multicolumn{11}{c}{ Average score } \\
\hline User type & $-\mathbf{6}$ & $-\mathbf{5}$ & $-\mathbf{4}$ & $\mathbf{- 3}$ & $\mathbf{- 2}$ & $\mathbf{- 1}$ & $\mathbf{0}$ & $\mathbf{1}$ & $\mathbf{2}$ & $\mathbf{3}$ & $\mathbf{4}$ & $\mathbf{5}$ & $\mathbf{6}$ & \\
\hline Consumer & 1 & 2 & 3 & 18 & 44 & 120 & 192 & 57 & 17 & 3 & 0 & 0 & 0 & -0.42 \\
\hline HCP & 0 & 0 & 0 & 7 & 9 & 50 & 131 & 71 & 18 & 9 & 2 & 0 & 0 & 0.18 \\
\hline Health organisation & 0 & 0 & 2 & 16 & 44 & 117 & 278 & 89 & 24 & 9 & 1 & 0 & 0 & -0.16 \\
\hline Media & 0 & 0 & 3 & 6 & 26 & 71 & 176 & 59 & 8 & 1 & 0 & 0 & 0 & -0.21 \\
\hline Other & 0 & 0 & 0 & 5 & 19 & 46 & 130 & 42 & 6 & 2 & 0 & 0 & 0 & -0.16 \\
\hline Unknown & 0 & 0 & 5 & 4 & 11 & 35 & 112 & 31 & 7 & 0 & 0 & 0 & 0 & -0.21
\end{tabular}

$\mathrm{HCP}=$ healthcare professional.

conversation, among the $\mathbf{5 0 0}$ million tweets sent each day. It is a global conversation but with more content about this subject being contributed by users from the UK. Consequently, this produced many tweets expressed through the lens of lived experience of the UK's NHS.

Themes of tweets shared by users suggests a negative view around the role of primary care in cancer, particularly during cancer diagnosis. Content shared by both consumers and the media often appeared to perpetuate attitudes and expressions of blame towards GPs. This negative attitude was

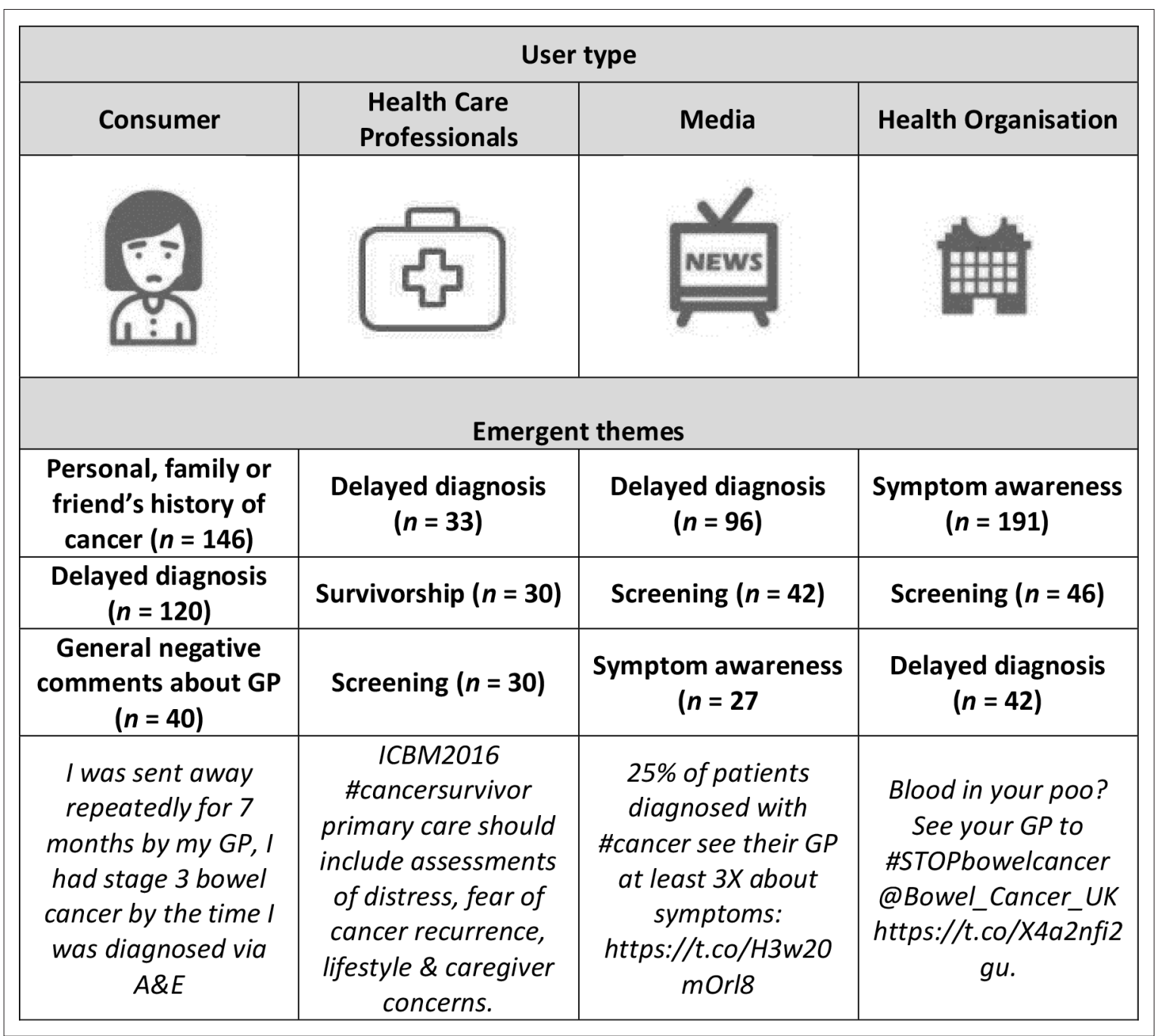

Figure 2 Emergent themes in cancer in primary care tweets by user type: consumers, media, healthcare professionals, and health organisations 


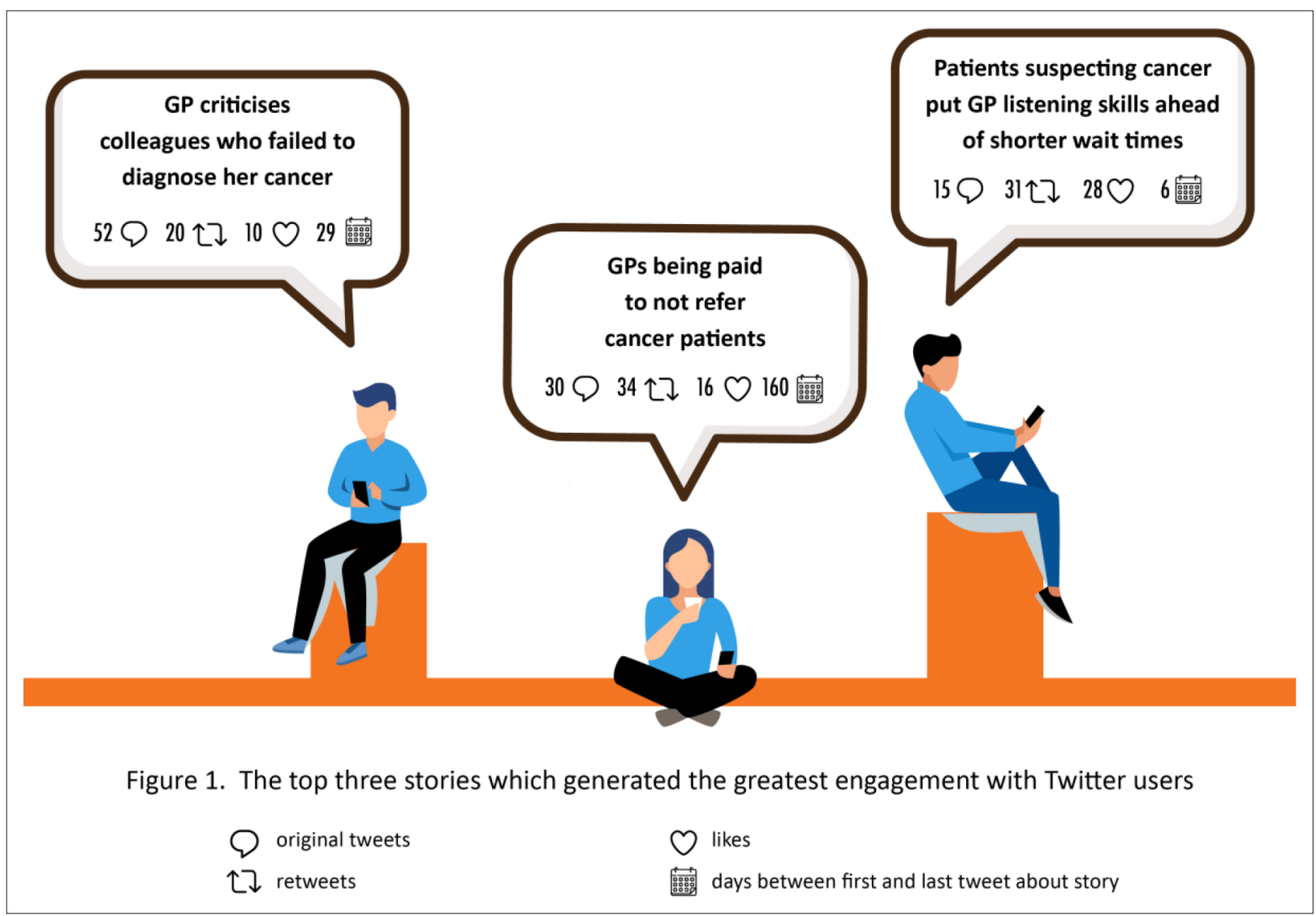

Figure 3 Top three stories that generated the greatest engagement with Twitter users

also clearly evidenced by the tweets that gained the most engagement. These stories highlighted that even though trending on Twitter is often short lived, it does have the capacity to continue to propagate negative content for months.

The negative sentiment expressed by consumers and media agencies warrants further consideration, particularly in the context of shaping the public's view of the importance of primary care across the cancer continuum. Negative bias presented by the media towards primary care in general has previously been demonstrated. ${ }^{51}$ A review of newspaper articles about neurological illnesses found that over $20 \%$ of articles contained medical errors, exaggerations, or stigmatising language. ${ }^{52}$ Primary care nurses have also reported their experiences of the influence of health stories reported in the media, which affected patient perceptions of care and the decisions they made about their care. ${ }^{53}$ In this respect, social media may both perpetuate the problem and be a solution to mediate public perception of cancer in primary care.

The content shared by HCPs suggest that this group use Twitter in a limited capacity. The themes in their tweets suggest they use it as a platform to share educational opportunities and resources with other HCPs. This is in line with other medical disciplines where the focus is on the potential of social media for HCPs in the context of educational and professional opportunities. ${ }^{18,19,21,22,24,30,33}$ The content of HCPs tweets also suggests little communication between GPs and consumers. Instead, the consumer relationship appeared to be nurtured by healthcare organisations, such as cancer-specific charities. Healthcare organisations also appeared to be the only group targeting multiple user groups, where their communications were targeted at HCPs, consumers, and the media.

Quantifying the impact of this conversation on Twitter is difficult, but it is reasonable to consider that a persistent negative perception could have an impact on the views and confidence of the general public in both their personal general practice and primary care more broadly with regards to cancer management, especially early diagnosis. The limited content identified about survivorship highlights there may be an opportunity to increase awareness of the role of primary care and GPs in this space. 


\section{Strengths and limitations}

This is the first study to explore the content and themes of tweets shared on Twitter about cancer in primary care. There are limited studies that have undertaken content analysis of tweets and the methodology of these studies is varied. Capturing all involved stakeholders and tweets is difficult given the multitude of potential search terms and combinations to capture relevant tweets.

This study deliberately used the search terms 'general practitioner' and 'GP', which is a common term in Australia and the UK, but may be less commonly used in other countries to describe primary care physicians. The use of the broader 'primary care' term could potentially relate to medical professional groups other than GPs or family physicians in the US. There is evidence in other oncology fields that the development of a specific taxonomy and/or hashtags can help focus discussion and identify relevant content. ${ }^{9}$ Promoting primary care-specific hashtags may be a way to better centralise and identify this conversation.

The study presented was performed retrospectively and used available data for a 2-year period up to mid-2017. Consequently, it may not represent the rapidly growing content on Twitter. Additionally, given English language was an inclusion criterion, the analysis of the countries where tweets were posted will be skewed towards English-speaking countries. There are limited data on the validity of using sentiment analysis in this context. Lastly, the analysis did not attempt to identify tweets from 'bot' accounts. Up to $15 \%$ of Twitter accounts may be automated 'bot' accounts. ${ }^{54}$ The study was unable to estimate the impact of these accounts on propagating tweets or specific tweet themes. The reasoning was that this study was about what content was shared and engaged with by users. As such, there was no impact on the analysis if the content was produced by an automated account or a live person.

\section{Comparison with existing literature}

This is the first study to explore the content of conversations on Twitter about cancer in primary care. A 2017 systematic review of Twitter as a tool for health research found that only $5 \%$ of included studies were focused on cancer. None of the studies identified explicitly involved primary care. The most common fields were public health, infectious disease, behavioural medicine, and psychiatry. ${ }^{55}$

\section{Implications for research and practice}

This study raises a question about if there is a need for primary care organisations to counter negative opinions and content around the role of primary care in cancer presented on Twitter. There is limited data on the impact of information shared by users on Twitter. In the age of influencers, understanding the spread and impact of content may help inform the development of targeted messages or awareness campaigns. It may also help identify primary care champions, users that are successfully supporting the role of primary care in cancer. In other disciplines, tweet chats have been used to engage in discussions with patients, although this has been limited to patients with breast and lung cancer. ${ }^{16,56}$

Cancer in primary care is a niche conversation on Twitter but one in which the media and consumers, and their cancer experiences feature prominently. Predominatly, these experiences were negative. There was a distinct absence of substantial positive promotion of primary care. Themes that emerged centred around perceived diagnostic delay, screening, and symptom awareness. As the role of primary care in cancer survivorship continues to grow there is an opportunity to increase awareness through Twitter and other social media platforms. Future research should explore the impact of negative sentiment on public perceptions of primary care and how organisations could influence sentiment within this platform to promote the importance of high-quality primary care across the cancer continuum.

Funding

Not applicable.

Ethical approval

As collection and analysis of these publicly available tweets was an observational study and did not require interaction with any human subjects it was exempt from institutional review.

\section{Provenance}


Freely submitted; externally peer reviewed.

Acknowledgements

This work was supported by the Primary Care Collaborative Cancer Clinical Trials Group (PC4).

\section{References}

1. Rubin G, Berendsen A, Crawford SM, et al. The expanding role of primary care in cancer control. Lancet Oncol 2015; 16(12): 1231-1272. DOI: https://doi.org/10.1016/S1470-2045(15)00205-3

2. Emery J. Cancer survivorship - the role of the GP. Aust Fam Physician 2014; 43(8): 521-525.

3. Nekhlyudov L, O'malley DM, Hudson SV. Integrating primary care providers in the care of cancer survivors: gaps in evidence and future opportunities. Lancet Oncol 2017; 18(1): e30-e38. DOI: https://doi.org/10.1016/S1470-2045( 16)30570-8

4. Pew Research Centre. Social media fact sheet. 2019; https://www.pewresearch.org/internet/fact-sheet/socialmedia/ (accessed 30 Sep 2020).

5. Zhao Y, Zhang J. Consumer health information seeking in social media: a literature review. Health Info Libr J 2017; 34(4): 268-283. DOI: https://doi.org/10.1111/hir.12192

6. Antheunis ML, Tates K, Nieboer TE. Patients' and health professionals' use of social media in health care: motives, barriers and expectations. Patient Educ Couns 2013; 92(3): 426-431. DOI: https://doi.org/10.1016/j.pec.2013.06. 020

7. Zhang AJ, Albrecht L, Scott SD. Using Twitter for data collection with health-care consumers. Int J Qual Methods 2018; 17(1): 160940691775078. DOI: https://doi.org/10.1177/1609406917750782

8. Prochaska JJ, Coughlin SS, Lyons EJ. Social media and mobile technology for cancer prevention and treatment. Am Soc Clin Oncol Educ Book 2017; 37: 128-137. DOI: https://doi.org/10.14694/EDBK_173841

9. Koskan A, Klasko L, Davis SN, et al. Use and taxonomy of social media in cancer-related research: a systematic review. Am J Public Health 2014; 104(7): e20-e37. DOI: https://doi.org/10.2105/AJPH.2014.301980

10. Keller DS, Winter DC, Pellino G, et al. \#colorectalresearch: introducing a disruptive technology for academic surgery in the social media age. Dis Colon Rectum 2018; 61(3): 279-280. DOI: https://doi.org/10.1097/DCR 0000000000001000

11. Struck JP, Siegel F, Kramer MW, et al. Substantial utilization of Facebook, Twitter, YouTube, and Instagram in the prostate cancer community. World J Urol 2018; 36(8): 1241-1246. DOI: https://doi.org/10.1007/s00345-018-22542

12. Attai DJ, Cowher MS, Al-Hamadani M, et al. Twitter social media is an effective tool for breast cancer patient education and support: patient-reported outcomes by survey. J Med Internet Res 2015; 17(7): e188. DOI: https:// doi.org/10.2196/jmir.4721

13. Pemmaraju N, Utengen A, Gupta V, et al. Social media and myeloproliferative neoplasms (MPN): analysis of advanced metrics from the first year of a new Twitter community: \#MPNSM. Curr Hematol Malig Rep 2016; 11(6): 456-461. DOI: https://doi.org/10.1007/s11899-016-0341-2

14. Jessup DL, Glover Iv M, Daye D, et al. Implementation of digital awareness strategies to engage patients and providers in a lung cancer screening program: retrospective study. J Med Internet Res 2018; 20(2): e52. DOI: https://doi.org/10.2196/jmir.8932

15. Kalia V, Ortiz DA, Patel AK, et al. Leveraging Twitter to maximize the radiology meeting experience. J Am Coll Radiol 2018; 15(1 Pt B): 177-183. DOI: https://doi.org/10.1016/j.jacr.2017.10.022

16. Himelboim I, Han JY. Cancer talk on Twitter: community structure and information sources in breast and prostate cancer social networks. J Health Commun 2014; 19(2): 210-225. DOI: https://doi.org/10.1080/10810730.2013. 811321

17. Lewis MA, Dicker AP, Media S. Social media and oncology: the past, present, and future of electronic communication between physician and patient. Semin Oncol 2015; 42(5): 764-771. DOI: https://doi.org/10.1053/j. seminoncol.2015.07.005

18. Massey PM, Budenz A, Leader A, et al. What drives health professionals to tweet About \#HPVvaccine? Identifying strategies for effective communication. Prev Chronic Dis 2018; 15: E26. DOI: https://doi.org/10.5888/pcd15. 170320

19. McGowan BS, Wasko M, Vartabedian BS, et al. Understanding the factors that influence the adoption and meaningful use of social media by physicians to share medical information. J Med Internet Res 2012; $14(5)$ : e117. DOI: https://doi.org/10.2196/jmir.2138

20. Pellino G, Simillis C, Qiu S, et al. Social media and colorectal cancer: a systematic review of available resources. PLoS One 2017; 12(8): e0183031. DOI: https://doi.org/10.1371/journal.pone.0183031

21. Pemmaraju N, Thompson MA, Qazilbash M. Disease-specific hashtags and the creation of Twitter medical communities in hematology and oncology. Semin Hematol 2017; 54(4): 189-192. DOI: https://doi.org/10.1053/j. seminhematol.2017.08.004

22. Thompson MA, Majhail NS, Wood WA, et al. Social media and the practicing Hematologist: Twitter 101 for the busy healthcare provider. Curr Hematol Malig Rep 2015; 10(4): 405-412. DOI: https://doi.org/10.1007/s11899-0150286-x 
23. Wilkinson SE, Basto MY, Perovic G, et al. The social media revolution is changing the conference experience: analytics and trends from eight international meetings. BJU Int 2015; 115(5): 839-846. DOI: https://doi.org/10. 1111/bju. 12910

24. Flynn $S$, Hebert $P$, Korenstein $D$, et al. Leveraging social media to promote evidence-based continuing medical education. PLoS One 2017; 12(1): e0168962. DOI: https://doi.org/10.1371/journal.pone.0168962

25. Lyson HC, Le GM, Zhang J, et al. Social media as a tool to promote health awareness: results from an online cervical cancer prevention study. J Cancer Educ 2019; 34(4): 819-822. DOI: https://doi.org/10.1007/s13187-0181379-8

26. Lenoir $\mathrm{P}$, Moulahi $\mathrm{B}, \mathrm{Azé} J$, et al. Raising awareness about cervical cancer using Twitter: content analysis of the 2015 \#SmearForSmear campaign. J Med Internet Res 2017; 19(10): e344. DOI: https://doi.org/10.2196/jmir. 8421

27. Vraga EK, Stefanidis A, Lamprianidis $G$, et al. Cancer and social media: a comparison of traffic about breast cancer, prostate cancer, and other reproductive cancers on Twitter and Instagram. J Health Commun 2018; 23(2): 181-189. DOI: https://doi.org/10.1080/10810730.2017.1421730

28. Xu S, Markson C, Costello KL, et al. Leveraging social media to promote public health knowledge: example of cancer awareness via Twitter. JMIR Public Health Surveill 2016; 2(1): e17. DOI: https://doi.org/10.2196/ publichealth. 5205

29. Shaban H. Twitter reveals its daily active user numbers for the first time. 2019; https://www.washingtonpost.com/ technology/2019/02/07/twitter-reveals-its-daily-active-user-numbers-first-time/ (accessed 1 Oct 2020).

30. Abuhadra N, Majhail NS, Nazha A. Impact of social media for the hematologist/oncologist. Semin Hematol 2017; 54(4): 193-197. DOI: https://doi.org/10.1053/j.seminhematol.2017.07.003

31. Nason GJ, O'Kelly F, Bouchier-Hayes D, et al. Twitter expands the reach and engagement of a national scientific meeting: the Irish Society of urology. Ir J Med Sci 2015; 184(3): 685-689. DOI: https://doi.org/10.1007/s11845015-1277-6

32. Pemmaraju N, Thompson MA, Mesa RA, Desai T. Analysis of the use and impact of Twitter during American Society of clinical oncology annual meetings from 2011 to 2016: focus on advanced metrics and user trends. J Oncol Pract 2017; 13(7): e623-e631. DOI: https://doi.org/10.1200/JOP.2017.021634

33. Bolderston A, Watson J, Woznitza N, et al. Twitter journal clubs and continuing professional development: An analysis of a \#MedRadJClub tweet chat. Radiography 2018; 24(1): 3-8. DOI: https://doi.org/10.1016/j.radi.2017.09. 005

34. Simcock R, Husain Z, Katz M. EP-1956: Twitter as a tool for radiotherapy medical education: The \#radonc Journal Club. Radiotherapy and Oncology 2016; 119: S928. DOI: https://doi.org/10.1016/S0167-8140(16)33207-8

35. Katz MS, Utengen A, Anderson PF, et al. Disease-Specific Hashtags for online communication about cancer care. JAMA Oncol 2016; 2(3): 392-394. DOI: https://doi.org/10.1001/jamaoncol.2015.3960

36. Diddi P, Lundy LK. Organizational Twitter use: content analysis of Tweets during breast cancer awareness month. J Health Commun 2017; 22(3): 243-253. DOI: https://doi.org/10.1080/10810730.2016.1266716

37. Vraga EK, Radzikowski JR, Stefanidis A, et al. Social media engagement with cancer awareness campaigns declined during the 2016 U.S. presidential election. World Med Health Policy 2017; 9(4): 456-465. DOI: https://doi. org/10.1002/wmh3.247

38. Crannell WC, Clark E, Jones C, et al. A pattern-matched Twitter analysis of US cancer-patient sentiments. J Surg Res 2016; 206(2): 536-542. DOI: https://doi.org/10.1016/j.jss.2016.06.050

39. Murthy D, Eldredge M. Who tweets about cancer? An analysis of cancer-related tweets in the USA. Digit Health 2016; 2(9): 205520761665767. DOl: https://doi.org/10.1177/2055207616657670

40. Nastasi A, Bryant T, Canner JK, et al. Breast cancer screening and social media: a content analysis of evidence use and guideline opinions on Twitter. J Cancer Educ 2018; 33(3): 695-702. DOI: https://doi.org/10.1007/s13187-017$1168-9$

41. Sutton J, Vos SC, Olson MK, et al. Lung cancer messages on Twitter: content analysis and evaluation. J Am Coll Radiol 2018; 15(1 Pt B): 210-217. DOI: https://doi.org/10.1016/j.jacr.2017.09.043

42. Tsuya A, Sugawara Y, Tanaka A, Narimatsu H. Do cancer patients tweet? Examining the Twitter use of cancer patients in Japan. J Med Internet Res 2014; 16(5): e137. DOI: https://doi.org/10.2196/jmir.3298

43. Emery JD, Shaw K, Williams B, et al. The role of primary care in early detection and follow-up of cancer. Nat Rev Clin Oncol 2014; 11(1): 38-48. DOI: https://doi.org/10.1038/nrclinonc.2013.212

44. Moreno MA, Goniu N, Moreno PS, Diekema D. Ethics of social media research: common concerns and practical considerations. Cyberpsychol Behav Soc Netw 2013; 16(9): 708-713. DOI: https://doi.org/10.1089/cyber.2012. 0334

45. National Health and Medical Research Council. National Statement on Ethical Conduct in Human Research. Canberra: The National Health and Medical Research Council the Australian Research Council and Universities Australia; 2007(updated 2018)

46. Vidal L, Ares G, Machín L, Jaeger SR. Using Twitter data for food-related consumer research: A case study on "what people say when tweeting about different eating situations". Food Qual Prefer 2015; 45: 58-69. DOI: https://doi.org/10.1016/j.foodqual.2015.05.006

47. RStudio Team. RStudio: Integrated Development for R. Boston, MA: RStudio; 2015. http://www.rstudio.com/

48. Rinker TW. sentimentr: calculate text polarity sentiment version 2.6.1. 2018; http://github.com/trinker/sentimentr

49. Hu M, Liu B. eds. Mining and summarizing customer reviews. Proceedings of the tenth ACM SIGKDD international conference on Knowledge discovery and data mining. New York, NY: Association for Comuting Machinery; 2004.

50. Liu B, Hu M, Cheng J. eds. Opinion observer: analyzing and comparing opinions on the web. Proceedings of the 14th international conference on world wide web. New York, NY: Association for Computing Machinery; 2005. 
51. Barry E, Greenhalgh T. General practice in UK newspapers: an empirical analysis of over 400 articles. Br J Gen Pract 2019; 69(679): e146-e153. DOI: https://doi.org/10.3399/bjgp19X700757

52. Caspermeyer JJ, Sylvester EJ, Drazkowski JF, et al. Evaluation of stigmatizing language and medical errors in neurology coverage by US newspapers. Mayo Clin Proc 2006; 81(3): 300-306. DOI: https://doi.org/10.4065/81.3. 300

53. van Bekkum JE, Hilton S. Primary care nurses' experiences of how the mass media influence frontline healthcare in the UK. BMC Fam Pract 2013; 14(1): 178. DOI: https://doi.org/10.1186/1471-2296-14-178

54. Varol O, Ferrara E, Davis CA. Online human-bot interactions: detection, estimation and characterization. 2017; https://arxiv.org/pdf/1703.03107.pdf (accessed 1 Oct 2020).

55. Sinnenberg L, Buttenheim AM, Padrez K, et al. Twitter as a tool for health research: a systematic review. Am J Public Health 2017; 107(1): e1-e8. DOI: https://doi.org/10.2105/AJPH.2016.303512

56. Klapper S. Social media and oncology: creating unprecedented opportunities for connecting and learning. 2015; https://connection.asco.org/magazine/features/social-media-oncology-creating-unprecedented-opportunitiesconnecting-learning (accessed 1 Oct 2020). 